\title{
PENGEMBANGAN DAYA TARIK WISATA DI DESA CANDIREJO, KABUPATEN MAGELANG
}

\author{
Janne Hillary ${ }^{1, a^{*}}$ dan Nurul Puspita ${ }^{2}$ \\ ${ }^{1,2}$ Magister Agribisnis, Fakultas Peternakan dan Pertanian, Universitas Diponegoro \\ ${ }^{\mathrm{a}}$ Hillaryjanne@gmail.com \\ * penanggung jawab
}

\begin{abstract}
ABSTRAK
Desa Candirejo merupakan salah satu wisata yang menitikberatkan nuansa alami pedesaan. Pendapatan masyarakat sebagian besar diperoleh dari pertanian. Hanya sebagian kecil yang bekerja di bidang pariwisata. Pemanfaatan Desa Candirejo sebagai ekowisata kurang optimal. Rata-rata jumlah pengunjung Desa Candirejo masih sedikit. Diperlukan pengelolaan dan pengembangan daya tarik wisata yang lebih baik untuk meningkatkan pendapatan masyarakat. Pengambilan sampel dilakukan akhir bulan Oktober 2016 secara accidental sampling. Pengumpulan data primer dan sekunder menggunakan metode observasi, penelusuran dokumen dan kuesioner. Analisis menggunakan metode deskriptif dan analisis SWOT. Tujuan dari penelitian ini adalah mengkaji dan menganalisis pengembangan daya tarik wisata di Desa Candirejo berdasarkan permintaan pengunjung. Dari hasil analisis ditemukan bahwa rencana pengembangan daya tarik wisata yang terpilih berdasarkan keinginan pengunjung terbanyak adalah atraksi seni. Inovasi atraksi seni dapat dilakukan dengan mengembangkan atraksi seni yang sudah ada atau memperlihatkan atraksi seni yang jarang ditampilkan ke pengunjung.
\end{abstract}

Kata kunci : Desa Candirejo, pengembangan, daya tarik wisata, atraksi seni

\section{Latar Belakang}

Dewasa ini, pariwisata merupakan salah satu dari industri gaya baru yang mampu menyokong pertumbuhan ekonomi yang sangat cepat. Pariwisata berkontribusi dalam menyediakan kesempatan kerja, pendapatan, taraf hidup dan dalam mengaktifkan sektor produksi lain di dalam negara yang memanfaatkan sektor pariwisata Fenomena ini muncul disebabkan oleh adanya beragam potensi yang dapat dikembangkan menjadi daya tarik wisata untuk berlibur dan melakukan aktivitas di luar rutinitas seharihari [1].

Indonesia memiliki peluang yang cukup besar untuk mengembangkan industri pariwisata karena kaya akan potensi sumberdaya yang dapat menghasilkan pendapatan dan mampu menjadikan modal pembangunan ditingkat lokal, regional maupun nasional [2]. Salah satu bentuk pengembangan industri pariwisata adalah memanfaatkan nuansa alami desa-desa di Indonesia sebagai desa wisata [3].

Desa Candirejo adalah desa yang berada dekat dengan situs warisan dunia Candi Borobudur, Kabupaten Magelang. Desa
Candirejo biasa dikenal dengan Desa Eco Tourism. Paket wisata yang diandalkan menitikberatkan pada Eco Tourism karena Desa Candirejo memiliki potensi alam yang menarik untuk dikunjungi dan sebagian penduduknya bekerja sebagai petani palawija seperti singkong, kacang - kacangan, cabai merah, jagung, dan lain - lain [3].

Pendapatan masyarakat sebagian besar diperoleh dari pertanian. Hanya sebagian kecil yang bekerja di bidang pariwisata [3]. Pemanfaatan Desa Candirejo sebagai ekowisata kurang optimal. Rata-rata jumlah pengunjung harian Desa Candirejo masih sedikit. Ditahun 2015, rata-rata jumlah pengunjung harian Desa Candirejo adalah 23 orang $[3,4]$.

Pengembangan daya tarik wisata diharapkan dapat memberikan kontribusi ekonomi, baik langsung maupun tidak langsung kepada masyarakat setempat, serta peningkatan kehidupan sosial [3,5]. Selain masyarakat setempat memperoleh manfaat dari kedatangan wisatawan, mereka pun dapat sekaligus menjaga dan mempertahankan budaya lokal serta pelestarian alam di wilayah mereka [3]. Peningkatan ekonomi dapat 
dilihat dari peningkatan pendapatan, peningkatan kesempatan kerja, peningkatan aset fisik, dan peningkatan nilai tanah [1].

Penelitian ini bertujuan untuk mengkaji dan menganalisis pengembangan daya tarik wisata di Desa Candirejo berdasarkan permintaan pengunjung. Hasil penelitian ini diharapkan dapat menjadi gambaran strategi yang tepat dalam mengembangkan daya tarik wisata di Desa Candirejo bagi pemerintah dan masyarakat.

\section{Metode}

Penelitian dilakukan di Desa Candirejo, Kabupaten Magelang dengan pertimbangan desa wisata merupakan trend pengembangan pariwisata pedesaan yang ada di Magelang. Penelitian dilaksanakan minggu terakhir pada bulan Oktober 2016.

Pengambilan sampel dilakukan secara accidental sampling. Responden merupakan seseorang yang kebetulan dijumpai atau ditemui saat itu [6]. Jumlah responden yang diambil adalah 31 orang, pemilihan responden ini ditentukan berdasarkan pertimbangan telah mencukupi syarat minimal jumlah sampel besar ( $\mathrm{n} \geq 30$ ), sehingga suatu data sampel diasumsikan berdistribusi normal untuk dapat diolah secara statistic [7].

Pada penelitian ini menggunakan data primer dan sekunder. Data primer diperoleh melalui observasi yang disertai dengan wawancara menggunakan kuesioner. Data sekunder didapat dari penelusuran dokumen serta data yang bersumber dari pengelola wisata di Desa Candirejo. Analisis yang digunakan untuk mengolah data adalah analisis deskriptif kualitatif dan analisis SWOT [5].

\section{Hasil dan Pembahasan}

Kondisi terkini pariwisata di Desa Candirejo dapat diketahui dari observasi langsung ke lapangan. Pengelola Desa Wisata di Desa Candirejo lebih condong menawarkan wisata mengelilingi desa yang sudah dalam bentuk paket dari pada atraksi-atraksi tertentu secara terpisah kepada turis asing dan domestik. Paket wisata tersebut berisi atraksiatraksi wisata, diantaranya kunjungan industri rumah tangga slondok, membuat gerabah, membuat kesenian anyaman dan bermain gamelan. Adapun kekuatan, kelemahan, peluang dan ancaman dari kegiatan wisata di Desa Candirejo dipaparkan sebagai berikut 
Tabel 1. Analisis SWOT Pariwisata Desa Candirejo

\begin{tabular}{|c|c|c|}
\hline FAKTOR INTERNAL & KEKUATAN (S) & KELEMAHAN (W) \\
\hline FAKTOR EKSTERNAL & $\begin{array}{l}\text { a) Partisipasi masyarakat dalam } \\
\text { mendukung pengembangan Desa } \\
\text { Wisata sangat kuat } \\
\text { b) Luas desa wisata yang relatif cukup } \\
\text { besar dengan potensi sumberdaya yang } \\
\text { melimpah sehingga berpotensi untuk } \\
\text { menambah jenis atraksi maupun paket } \\
\text { wisata } \\
\text { c) Tata cara kehidupan dan penghidupan } \\
\text { serta budaya masyarakat tradisional } \\
\text { perdesaan yang masih kental }\end{array}$ & $\begin{array}{l}\text { a) Desa Candirejo berada dalam } \\
\text { zona bahaya Gunung Merapi } \\
\text { karena berada dekat dengan } \\
\text { puncak Merapi } \\
\text { b) Promosi tentang Desa Wisata } \\
\text { Candirejo masih kurang } \\
\text { c) Sumberdaya manusia masyarakat } \\
\text { yang paham pengelolaan desa } \\
\text { wisata masyarakat masih sedikit. } \\
\text { d) Keterbatasan finansial/modal } \\
\text { dalam rangka pengembangan } \\
\text { desa wisata }\end{array}$ \\
\hline PELUANG $(\mathrm{O})$ & $\begin{array}{l}\text { ARAHAN PENGEMBANGAN } \\
\text { STRATEGI S + O }\end{array}$ & $\begin{array}{l}\text { ARAHAN PENGEMBANGAN } \\
\text { STRATEGI } \mathrm{W}+\mathrm{O}\end{array}$ \\
\hline $\begin{array}{l}\text { a) Telah ada kesepakatan } \\
\text { pengembangan Desa Wisata } \\
\text { dengan stake holder - stake } \\
\text { holder terkait. } \\
\text { b) Animo dan minat wisatawan } \\
\text { untuk berkunjung ke Desa } \\
\text { Candirejo yang terus bertambah } \\
\text { c) Secara regional dekat dengan } \\
\text { jalan utama Yogyakarta- } \\
\text { Magelang } \\
\text { d) Semakin banyak masyarakat } \\
\text { yang mendukung pariwisata } \\
\text { perdesaan }\end{array}$ & $\begin{array}{l}\text { 1. Merealisasikan kerjasama antara pihak } \\
\text { Desa Wisata Candirejo dengan pihak- } \\
\text { pihak/stakeholder terkait } \\
\text { 2. Mengoptimalkan potensi alam sosial dan } \\
\text { budaya serta peran masyarakat dalam } \\
\text { mengembangkan inovasi dan variasi } \\
\text { atraksi Desa Candirejo guna } \\
\text { meningkatkan kunjungan wisatawan }\end{array}$ & $\begin{array}{l}\text { 1. Mengoptimalkan kerjasama } \\
\text { antara pihak pengelola Desa } \\
\text { Candirejo dengan stake holder } \\
\text { terkait baik itu pemerintah } \\
\text { maupun swasta guna } \\
\text { meningkatkan promosi dan } \\
\text { investasi Desa } \\
\text { Candirejokembnag } \\
\text { 2. Meningkatkan kualitas } \\
\text { sumberdaya manusia yang } \\
\text { dimiliki Desa Candirejo agar } \\
\text { kualitas pelayanan terhadap } \\
\text { wisatawan dapat lebih optimal }\end{array}$ \\
\hline ANCAMAN (T) & $\begin{array}{c}\text { ARAHAN PENGEMBANGAN } \\
\text { STRATEGI S + T }\end{array}$ & $\begin{array}{l}\text { ARAHAN PENGEMBANGAN } \\
\text { STRATEGI } \mathrm{W}+\mathrm{T}\end{array}$ \\
\hline $\begin{array}{l}\text { a) Munculnya kompetitor Desa } \\
\text { Wisata lainnya yang memiliki } \\
\text { daya tarik yang lebih besar } \\
\text { b) Budaya yang kurang baik yang } \\
\text { mungkin dibawa oleh } \\
\text { wisatawan yang berkunjung. }\end{array}$ & $\begin{array}{l}\text { 1. Menonjolkan ciri khas dan daya saing } \\
\text { yang dimiliki serta mengoptimalkan } \\
\text { potensi alam sosial dan budaya serta } \\
\text { peran masyarakat dalam } \\
\text { mengembangkan inovasi dan variasi } \\
\text { atraksi di Desa Candirejo guna } \\
\text { meningkatkan kunjungan wisatawan } \\
\text { 2. Tetap menjaga kualitas dan tradisi serta } \\
\text { tata cara kehidupan dan penghidupan } \\
\text { serta budaya masyarakat tradisional } \\
\text { perdesaan yang masih asli sehingga } \\
\text { tidak terpengaruh budaya yang negatif }\end{array}$ & $\begin{array}{l}\text { 1. Mengoptimalkan promosi yang } \\
\text { menonjolkan ciri khas dan } \\
\text { keunggulan Desa Candirejo } \\
\text { sebagai daya tarik wisata } \\
\text { 2. Membimbing kaum muda } \\
\text { setempat supaya dapat } \\
\text { menyaring arus modernisasi dan } \\
\text { menyalurkan potensinya dalam } \\
\text { mengelola desa wisata }\end{array}$ \\
\hline
\end{tabular}

Bedasarkan analisis SWOT di atas diketahui diperlukan adanya strategi pengembangan wisata untuk mengoptimalkan kekuatan, memperbesar peluang, menutup kelemahan dan memperkecil ancaman sehingga jumlah pengunjung dapat meningkat. Salah satu bentuk strategi tersebut adalah mengembangkan inovasi dan variasi daya tarik wisata di Desa Candirejo. Adapun hasil dari keinginan pengunjung dalam pengembangan daya tarik wisata tersaji pada gambar di bawah ini:

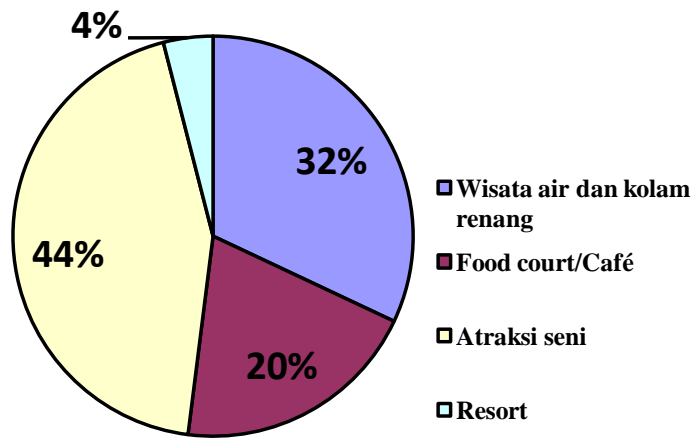

Gambar 1. Proporsi Permintaan Pengunjung Terhadap Pengembangan Daya Tarik Wisata 
Pengunjung Desa Candirejo menginginkan adanya penambahan daya tarik wisata diantaranya wisata air dan kolam renang, food court atau kafe, atraksi seni dan (waterboom dan kolam renang), atraksi kesenian dan resort.

Sebagian kecil pengunjung (4\%) menghendaki adanya resort sebagai daya tarik wisata Desa Candirejo. Sebenarnya saat ini Desa Candirejo telah menawarkan rumah singgah untuk pengunjung yang ingin merasakan lebih lama nuansa alami pedesaan. Kondisi rumah yang dijadikan rumah singgah sebagian besar masih beralaskan tanah. Ketradisionalan tersebut merupakan suatu hal yang unik dan seringkali dicari wisatawan. Namun, keunikan ini tidak diimbangi dengan kebersihan dan tata ruang yang baik. Rumah singgah terkesan ala kadarnya dan kurang indah dipandang. Penataan rumah singgah yang baik dengan melibatkan ahli arsitektur dapat meningkatkan nilai jual rumah singgah kepada wisatawan.

Desa Candirejo memiliki potensi alam yang menarik untuk dikunjungi. Salah satunya adalah sungainya yang jernih. Namun wisata air ini masih kurang menarik minat kunjung wisatawan. Beberapa pengunjung (32\%) menghendaki adanya pengembangan aktivitas air di Desa Candirejo. Wisata sungai yang ada diharapkan bisa didampingi dengan produk wisata tambahan seperti susur sungai dengan perahu karet, outbound atau adanya jembatan kayu yang menghubungkan bibir bibir sungai. Selain inovasi dari wisata sungai, wisatawan juga menginginkan adanya fasilitas kolam renang yang menyatu dengan alam. Air di kolam renang tersebut bisa bersumber dari pegunungan yang memang dekat dengan Desa Candirejo.

Keberadaan Desa Candirejo sebagai desa wisata belum didukung ketersediaan tempat makan. Pengelola menyiapkan makanan ringan atau berat bercitarasa Jawa Tengah hanya saat ada pesanan, pesanan-pun harus dilakukan jauh-jauh hari. Hal tersebut menjadi suatu hal yang tidak disukai sebagian pengunjung. Sejumlah pengunjung (20\%) menghendaki adanya pengembangan wisata berupa tempat makan berupa foodcourt atau kafe. Tempat makan ini dapat digunakan sebagai sarana bersantai setelah seharian berkeliling desa ataupun sebagai wisata kuliner.

Sebagai tempat wisata yang menonjolkan nuansa alami pedesaan dan aktivitas masyarakatnya, Desa Candirejo juga menyuguhkan atraksi kesenian setempat. Alat musik tradisional, gamelan, yang merupakan hiburan utama masyarakat, disuguhkan ke wisatawan yang berkunjung. Pengunjung langsung dipersilakan memainkan lagu-lagu Jawa dengan gamelan tanpa diberikan aktivitas pengantar yang memperkenalkan gamelan tersebut. Dalam durasi yang lama, permainan gamelan akan terasa monoton. Diperlukan adanya inovasi dan variasi dalam mengajak wisatawan menabuh gamelan, seperti memberikan games perkenalan.

Desa Candirejo kaya akan seni budaya. Tidak hanya permainan gamelan, Desa Candirejo juga memiliki kethoprak, wayang kulit, jatilan, kobro, topeng ireng atau dayakan, gatoloco, sholawatan, rebana dan lain-lain. Kekayaan seni budaya ini sangat menarik minat wisatawan untuk berkunjung. Sayangnya, apabila ada wisatawan yang ingin menonton kesenian ini harus pesan dulu beberapa hari sebelumnya. Sehingga bagi wisatawan yang datang secara spontan tanpa perjanjian tidak dapat melihat kesenian tersebut. Dari hasil penelitian dapat diketahui, permintaan pengembangan daya tarik wisata tertinggi adalah pengembangan atraksi seni (44\%). Pengunjung menginginkan adanya pagelaran seni budaya yang bisa dilihat saat berkunjung, tidak hanya bermain gamelan saja. Pengunjung merasa senang bila diikutsertakan dalam pentas seni mayarakat setempat, untuk menari dan bernyanyi Jawa bersama. Juga ikut mengenakan kostum pentas seni yang dikenakan masyarakat Desa Candirejo. Membaur dengan seni budaya setempat dinyatakan sebagai hal yang berbeda menyenangkan saat berwisata di Desa Candirejo.

\section{Kesimpulan}

Dibutuhkan adanya pengembangan daya tarik wisata di Desa Candirejo, yaitu penambahan wisata air dan kolam renang, tempat makan, atraksi seni dan resort. Proporsi permintaan pengunjung terhadap pengembangan daya tarik wisata adalah atraksi seni $44 \%$, wisata 
air dan kolam renang 32\%, foodcourt $20 \%$

dan resort 4\%. Adapun rencana pengembangan daya tarik wisata yang terpilih berdasarkan keinginan pengunjung terbanyak adalah atraksi seni. Inovasi atraksi seni dapat dilakukan dengan mengembangkan atraksi seni yang sudah ada atau memperlihatkan atraksi seni yang jarang ditampilkan ke pengunjung. Pengembangan daya tarik wisata secara keseluruhan sebaiknya memprioritaskan strategi $\mathrm{S}-\mathrm{O}$ yang menggunakan kekuatan kerjasama dengan pihak-pihak/stakeholder terkait, serta mengoptimalkan potensi alam sosial dan budaya serta peran masyarakat dalam mengembangkan inovasi dan variasi atraksi Desa Candirejo guna meningkatkan kunjungan wisatawan.

\section{Referensi}

[1] U. Gokovali, O. Bahar, Contribution of Tourism to Economic Growth: A Panel Data Approach, 2006, Anatolia 17 (2) 25.

[2] Kementerian Perdagangan Republik Indonesia, Warta Ekspor, Jakarta, 2011, hal. 4-6.

[3] I. K. Permanasari, Pemberdayaan Masyarakat Melalui Desa Wisata Dalam Usaha Peningkatan Kesejahteraan (Desa Candirejo, Magelang, Jawa Tengah), Tesis UI, 2011.

[4] E. Handriana, Menggugah Desa Wisata Jawa http://berita.suaramerdeka.com/ menggugah-desa-wisata-jawa-tengah/, 2015, Diakses 17 nov 2016, pukul 20.47.

[5] R. Setiawan, B. Sunaryo, Pengembangan Agrowisata Kawasan Rambat - Waduk Kedungombo, Kabupaten Grobogan, 2013, Jtpwk 2 (1) 42-44.

[6] B.T. Premono, A. Kunarso, Pengaruh Perilaku Pengunjung Terhadap Jumlah Kunjungan Di Taman Wisata Alam Punti Kayu Palembang, 2008, Jurnal Penelitian Hutan dan Konservasi Alam V (5) 425.

[7] A. Delice, The Sampling Issues in Quantitative Research, 2010, Educational Sciences: Theory \& Practice 10 (4) 2008 